\title{
Low HbA1c and Increased Mortality Risk-is Frailty a Confounding Factor?
}

\author{
Ahmed H Abdelhafiz ${ }^{1}$, Alan J Sinclair ${ }^{2}$ \\ ${ }^{1}$ Consultant Physician and Honorary Senior Clinical Lecturer, Department of Elderly Medicine, Rotherham \\ General Hospital, Rotherham, S60 2UD, UK \\ ${ }^{2}$ Dean and Professor of Medicine, Institute of Diabetes for Older People (IDOP), Bedfordshire \&, Hertfordshire \\ Postgraduate Medical School, University of Luton, Puteridge Bury Campus, Bedfordshire, LU2 8LE, UK
}

[Received September 9, 2014; Revised October 17, 2014; Accepted October 22, 2014]

\begin{abstract}
Diabetes mellitus is increasingly becoming an older person disease due to the increased survival and aging of the population. Previous studies which showed benefits of tight glycemic control and a linear relationship between HbA1c and mortality have largely included younger patients newly diagnosed with diabetes and with less comorbidities. Recent studies, which included older population with diabetes, have shown a U-shaped relationship of increased mortality associated with low HbA1c. The mechanism of such relationship is unclear. There was no direct causal link between low HbA1c and mortality. It appears that malnutrition, inflammation and functional decline are characteristics shared by the populations that showed increased mortality and low HbA1c. In these studies functional status, disability or frailty was not routinely measured. Therefore, although adjustment for comorbidities was made there may be a residual confounding by unmeasured factors such as frailty. Thus, frailty or decline in functional reserve may be the main confounding factor explaining the relationship between increased mortality risk and low HbA1c.
\end{abstract}

Key words: Frailty, Mortality, Diabetes, Low HbA1c

The evidence suggesting that patients with type 2 diabetes should have their HbA1c less than $7 \%$ is largely based on the findings from the United Kingdom Prospective Diabetes Study (UKPDS) which showed that intensive glycemic control (HbAlc 7.0\%) reduced the rate of microvascular complications by $25 \%$ compared with less tight control (HbA1c 7.9\%) although reduction of cardiovascular disease did not reach statistical significance $(\mathrm{p}=0.052)$ [1]. An observational analysis of the UKPDS data found that each $1 \%$ reduction of $\mathrm{HbA} 1 \mathrm{c}$ reduces all-cause mortality and myocardial infarction by $14 \%$ establishing the concept of "the lower the better" [2]. However, subsequent evidence from randomised clinical trials was unable to confirm that tight glycemic control (HbA1c $<6.5 \%)$ reduces cardiovascular events and the Action to Control Cardiovascular Risk in Diabetes (ACCORD) study has shown even an increased risk of mortality [3-5]. The UKPDS was a trial of younger population excluding those above the age of 65 years and included only newly diagnosed patients with type 2 diabetes who have less comorbidities and in whom vascular damage from long-term exposure to hyperglycemia may not yet have occurred. In younger patients with less comorbidities, elevated $\mathrm{HbAlc}$ may act as a risk factor for long term adverse outcomes but in older patients with multiple comorbidities low $\mathrm{HbA} 1 \mathrm{c}$ may be associated with increased mortality. We hypothesise that frailty may be unmeasured or less 
recognised factor associated with both the predictor (low $\mathrm{HbAlc}$ ) and the outcome (increased mortality), in other word a confounding factor. Therefore, this article investigates the changes in diabetes epidemiology since the publication of the UKPDS in 1998, reviews the observational clinical studies that showed increased mortality with low HbA1c and explores the increased prevalence of comorbidities and the emergence of frailty in older people with diabetes and its impact on the relationship between low HbA1c and risk of mortality.

\section{Methods}

We have performed a search of Medline and Embase for observational studies from January 1969 to April 2014 using keywords relating to low HbAlc or intensive glycemic control and mortality risk in patients with type 2 diabetes. Only English language studies were selected. Articles were reviewed for relevance by abstract. A manual review of citations in retrieved articles was performed in addition to the electronic literature search. The final list of cited studies was chosen on the basis of relevance to the topic of this review.

\section{The epidemiology shift}

The worldwide prevalence of diabetes is rising with increasing age. As life expectancy increased due to a decline in cardiovascular mortality there appears to be an epidemiologic shift for diabetes from being a disease of middle age to a disease of older people [6]. In France, the prevalence has increased to $14.2 \%$ in those aged $65-$ 74 years, peaking at $19.7 \%$ in men and $14.2 \%$ in women aged 75-79 years and more than half of those with diabetes were $\geq 65$ years [7]. In the US, the prevalence of diabetes increased by $75 \%$ across all age groups from 1988-1994 to 2005-2010, but adults $\geq 65$ years of age experienced the largest increase. Younger adults (20-34 years of age) had the lowest absolute increase in diabetes prevalence of $1.0 \%$, followed by middle-aged adults (35-64) at $2.7 \%$ and older adults $(\geq 65)$ at $10.0 \%$ (all $P<$ 0.001) [8]. The current total diabetes prevalence is estimated to be $14 \%$ of the population but by the year 2050 diabetes prevalence could be as high as $33 \%$ of the whole population and is expected to be highest in those aged $\geq 65$ years [9]. However, many older people with diabetes remain undiagnosed. In the National Health and Nutrition Examination Survey the prevalence of diagnosed diabetes in those $\geq 75$ years old was $14.9 \%$, undiagnosed diabetes based on fasting plasma glucose and 2 hours oral glucose tolerance test was $13.4 \%$. This makes a total prevalence of diagnosed and undiagnosed diabetes of $28.3 \%$. Pre-diabetes defined as either impaired fasting glycemia (IFG) or impaired glucose tolerance (IGT) was prevalent in $46.7 \%$ of those $\geq 75$ years old. Therefore, the total prevalence of diabetes (diagnosed and undiagnosed) and pre-diabetes (IFG and IGT) reaches a peak of around $75 \%$ of older people $\geq 75$ years of age [10]. In older people, diabetes is a disabling disease and is associated with high comorbidity burden and geriatric syndromes such as cognitive dysfunction, physical disability, under nutrition, falls, fractures and incontinence leading to increased risk of nursing home admission by three fold [11]. In nursing homes, the prevalence of diabetes is higher affecting up to $32.8 \%$ of residents and subjects with diabetes tend to have a greater comorbid burden, more medications, and have more hospitalizations than residents with no diabetes [12].

\section{The comorbidity shift and emergence of frailty}

With the epidemiologic shift of the prevalence of diabetes towards old age, diabetes in older people is associated with coexistent multiple comorbid conditions as well as geriatric syndromes rather than existing as a single disease as in younger counterparts.

\section{Comorbidity burden}

Diabetes in old age is associated with comorbid chronic diseases and as many as $40 \%$ of older people with diabetes have at least three comorbid conditions [13]. The comorbidity burden is even higher in care home residents with diabetes. For example, they have more cardiovascular disease, visual problems, pressure sores, limb amputations and kidney failure than residents without diabetes [14]. In a retrospective case note review of 75 nursing home residents with diabetes in the UK, very significant levels of disability has been shown in areas of continence, feeding, mobility and communication. Each individual had a mean of four comorbidities (range 1-8) [15]. In another study, residents with diabetes had a greater comorbidity burden, more prescribed medications and experienced more hospitalizations (37\% vs 18\%) than residents without diabetes. Geriatric syndromes such as cognitive and physical dysfunction, depression, falls and urinary incontinence are common in older people with diabetes. Due to the effect of diabetes on physical function, the risk of disability in performing activities of daily living is increased by two fold compared to those without diabetes [16]. Diabetes is also associated with reduced muscle strength, poor muscle quality, accelerated loss of lower extremity strength and muscle mass contributing further to physical limitation [17]. 


\section{Frailty burden}

Frailty is a condition characterized by a reduction in physiological reserve and in the ability to resist physical or psychological stressors [18]. Its definition is largely based on the presence of three or more phenotypes (weight loss, weakness, decreased physical activity, exhaustion and slow gait speed) [19]. The rate of progression of frailty increases with age and is likely due to diminishing physiologic reserve with ageing however, the presence of brain pathologies such as cerebrovascular and Alzheimer's diseases accelerates the rate of progression [20]. The biological processes that underlie frailty are still unclear and likely to be complex and multifactorial. The physiological systems believed to be associated with frailty phenotype are the cardiovascular, neuroendocrine, metabolic, immune, and nervous systems [21]. Frailty has also been shown to be associated with exaggerated glucose and insulin responses after 2-hour oral glucose tolerance test in individuals without diabetes which suggests that these individuals have reduced physiologic reserve and dysregulation of glucose challenge is a component of the physiologic vulnerability associated with frailty [22]. Frailty is viewed as a wasting disease with weight loss being one of its criteria. Under nutrition which is very common in older people, seems to be a risk factor for frailty. In the US, about $16 \%$ of elderly persons living in the community are undernourished. These figures rise to $59 \%$ in long-term care institutions and $65 \%$ in acute care hospitals [23]. Sarcopenia or muscle mass loss is a component of frailty which seems to be accelerated when diabetes is present. In a community study of 3,153 participants $\geq 65$ years of age, appendicular lean mass loss in men with diabetes was twice that of men without diabetes $(3.0 \%$ vs $1.5 \%)$ and in women with diabetes was 1.8 times that of those without diabetes $(3.4 \%$ vs $1.9 \%$ ) over 4 years of follow up. The mechanisms explaining these results may be related to reduced muscle protein synthesis due to lower testosterone and insulin like growth factor 1 and increased muscle protein breakdown due to a higher rate of inflammation [24]. Diabetes also causes sarcopenia due to the catabolic effect of insulin deficiency and by increasing intramyocellular lipid accumulation [25]. In another study, older persons with type 2 diabetes had accelerated decline in leg lean mass, muscle strength, and longer sitto-stand time compared to normoglycemic control subjects [26]. Other factors may be related to the oral health of older people with diabetes. For example optimal nutrition may not be maintained due to poor dentition, a dry mouth, reduced taste sensation, palatability and appetite change with increasing age [27].

\section{The evidence shift}

Since the publication of the UKPDS, the concept of low is better was the norm. However, with the epidemiologic shift of diabetes towards older age and its associated comorbidities there appears to be a shift in the evidence with tighter glycemic control seems to be associated with increased mortality. Three studies were reported from Kaiser Permanente cohorts. The first was an observational study of 26,673 patients with type 2 diabetes which showed increased all-cause mortality among those with a mean $\mathrm{HbA} 1 \mathrm{c}<6.0 \%$ (17.5 per 1,000 person-years, 95\% CI 15.8 to 19.4 ) and those with a mean $\mathrm{HbAlc} 6.0 \%$ to $6.4 \%$ (13.1 per 1,000 person-years, 95\% CI 12.0 to 14.3 ) compared to those with HbAlc $7.0 \%$ to $7.4 \%$ adjusted for demographic and clinical characteristics after 6 years of follow up [28]. The second was a retrospective study of 71,092 patients with type 2 diabetes, mean (SD) age 71.0 (7.4) and 14.6\% were $>80$ years, which showed lower mortality risk for HbA1c levels between 6.0 and $9.0 \%$ compared with HbA1c $<6.0 \%$ after a mean of 3.1 years of follow up [29]. The third was a case control study of 44,628 control subjects matched to 11,157 cases for age and gender, mean (SD) age 65.5 (10.5). Patients with the lowest $\mathrm{HbAlc}$ levels (median 6.4\%) were at a $52 \%$ increased risk for all-cause mortality relative to patients with a median $\mathrm{HbAlc} 7.5 \%$ after 3 years of follow up [30]. Two studies of patients with diabetes and heart disease reported similar results. The first was a prospective study for patients undergoing heart surgery which showed that low HbA1c $(<5.7 \%)$ was associated with increased late postoperative mortality only in patients with heart failure but not in those without [31]. The second was a retrospective study of 5,815 veterans with heart failure and diabetes which showed that the lowest quintile $(\mathrm{HbA} 1 \mathrm{C} \leq 6.4 \%)$ had significantly increased risk of mortality when compared with the middle quintile $(7.1 \%<\mathrm{HbA} 1 \mathrm{c} \leq 7.8 \%)$, hazard ratio (HR) $1.37,95 \%$ CI 1.14 to $1.64, \mathrm{p}=0.001$ adjusted for potential confounders after 2 years of follow up [32]. Two other studies of patients with diabetes and renal disease had the same conclusion. The first was a population based cohort study of 23,296 patients with diabetes and chronic kidney disease, defined as glomerular filtration rate $<60.0 \mathrm{~mL} / \mathrm{min} / 1.73 \mathrm{~m}^{2}$, which showed that low HbAlc $(<6.5 \%)$ was associated with increased mortality [33]. The second was a cohort study of 54,757 patients with diabetes on maintenance hemodialysis, mean (SD) age 63 (13) years, which showed that adjusted HR for mortality was inversely related to HbAlc levels. For HbA1c $6.0-6.9 \%$, HR was 1.05 (95\% CI 1.01 to 1.08$)$, HbA1c 5.0-5.9\% (1.08, 1.04 to 1.11$)$ and $\mathrm{HbA} 1 \mathrm{c} \leq 5 \%(1.35,1.29$ to 1.42$)$ compared 
with HbA1c 7.0-7.9\%. Low HbA1c was related to markers of poor nutrition. The likelihood of having low baseline $\mathrm{HbA} 1 \mathrm{c}<6 \%$ was associated with lower values for body mass index, albumin, creatinine, and normalized protein catabolic rate (nPCR) levels, indicating a link between $\mathrm{HbAlc}$ level and malnutrition and inflammation burden. Each $\mathrm{g} / \mathrm{dL}$ increase in serum albumin (OR 0.90, 95\% CI 0.86 to 0.94 ) and blood hemoglobin level $(0.87,0.86$ to 0.88$)$, each $\mathrm{g} / \mathrm{Kg} /$ day increase of nPCR $(0.55,0.51$ to 0.59$)$, and each $\mathrm{Kg} / \mathrm{m}^{2}$ increase in BMI level $(0.93,0.92$ to 0.94$)$ translated into a $10,13,45$, and $7 \%$ lower risk of HbA1c level $<6 \%$, respectively [34]. Other studies of general diabetes population mirror the same results. In a retrospective British general practice study of 47,970 patients $(\geq 50$ years old) with type 2 diabetes, all-cause mortality was higher for low HbA1c (median 6.4\%, IQR 6.1-6.6\%) compared to patients with $\mathrm{HbA} 1 \mathrm{c}$ decile with the lowest hazard (median HbAlc 7.5\%, IQR 7.5-7.6\%, adjusted HR $1.52,95 \%$ CI 1.32 to 1.76 ) [35]. In a case control study of 16,585 mortality cases of type 2 diabetes matched for age and gender to a similar number of living controls, low HbAlc $(<6.5 \%)$ values were associated with increased odds of all-cause mortality (OR 1.22, CI 1.11 to 1.34$)$ in comparison to normal HbAlc levels $(6.5 \%$ to $9 \%)$ after adjustment for study confounders after a median follow up of 3.7 years [36]. In another case control study of 427 mortality cases of type 2 diabetes matched for age, gender, body mass index, comorbidities and duration of diabetes to an equal number of living controls lower HbAlc $(<6.5 \%)$ was associated with a higher risk of mortality but it did not reach statistical significance possibly due to small sample size [37]. The shift of evidence was similar in even subjects without diabetes. In the National Health and Nutrition Examination Survey III of 14,099 participants without diabetes, an $\mathrm{HbA} 1 \mathrm{c}<4.0 \%$ versus $5.0 \%$ to $5.4 \%$ was associated with an increased risk of all-cause mortality (HR 3.73; 95\% CI 1.45 to 9.63) after a median follow-up of 8.8 years [38]. Although frailty was not directly measured in these studies, the cohorts of patients showing increased mortality with lower HbAlc were consistently older with high prevalence of multiple comorbidities, weight loss and malnutrition (Table 1).

\section{Low HbA1c and mortality}

\section{Causal link}

Decreased survival in patients achieving low $\mathrm{HbAlc}$ levels might be related to hypoglycemia which is a common complication of intensive blood glucose control. In the Veterans Affairs study, more than one episode of severe hypoglycemia was associated with an
$88 \%$ rise in relative risk for sudden death [39]. In the intensive control arm of the ACCRD study mortality was higher among participants who experienced at least one episode of serious hypoglycemia (2.8\%) compared to those with no episodes (1.2\%), adjusted HR $1.41,95 \%$ CI 1.03 to 1.93 . A similar pattern was observed in the conventional treatment arm (3.7\% vs $1 \%)$ adjusted HR $2.30,95 \%$ CI 1.46 to 3.65 . However, among participants who experienced at least one episode of hypoglycemia requiring medical assistance the risk of death was significantly lower in such participants in the intensive arm than in the standard arm (adjusted HR 0.55, 95\% CI 0.31 to 0.99 ). This confirms that low HbA1c does not appear to be a direct cause of mortality as symptomatic severe hypoglycemia did not appear to account for the difference in mortality between the two study arms of the ACCORD study. Other unmeasured factors could be related to such increased mortality. One explanation is that severe hypoglycemia may have been a potent marker of underlying illness or frailty in the standard treatment arm, whereas in the intensive treatment arm severe hypoglycemia was instead likely to be the result of excessive hypoglycemic treatment. These findings raise the possibility that hypoglycemic episode may not be an immediate contributor to death but susceptibility to hypoglycemia may be a marker for an underlying disorder such as frailty that increases the risk for death in patients with diabetes [40]. In the Preterax and Diamicron Modified Release Controlled Evaluation (ADVANCE) study, hypoglycemia was strongly associated with increased risks of cardiovascular and non cardiovascular mortality. This association was independent of tight glycemic control. It is likely that hypoglycemia was related to the negative effects of the associated comorbidities and was a marker of an increased vulnerability to adverse clinical outcomes rather than a direct cause of the events. The risk estimates were markedly attenuated after adjustment for the associated comorbidities suggesting that the effects of confounding factors were substantial. It is possible that the presence of coexisting comorbidities could increase a patient's vulnerability to both hypoglycemia and an adverse outcome in the absence of a direct causal link between the two [41]. However, a recent metaanalysis suggests that severe hypoglycemia is associated with twice the risk of cardiovascular events and this association is not entirely explained by the associated comorbidities but could be related to unmeasured factors [42]. The possibility that factors other than tight glucose control may explain the association of low HbA1c with increased mortality risk is also supported by the fact that a U-shaped relationship of mortality and HbAlc was observed in non diabetic population [43]. 
Table 1: Summary of observational studies reporting increased mortality with low HbA1c

\begin{tabular}{|c|c|c|c|c|}
\hline Study & Design & Population & $\begin{array}{l}\text { Cut off } \\
\text { HbA1c* }\end{array}$ & Characteristics of patients with low HbA1c \\
\hline Engoren et al, 2013 & Prospective & $\begin{array}{l}\text { Diabetics } \\
\text { undergoing heart } \\
\text { surgery }\end{array}$ & $5.7 \%$ & $\begin{array}{l}\text { Older, having myocardial infarctions, smokers, } \\
\text { needed blood transfusions, and concomitant valve } \\
\text { surgery. }\end{array}$ \\
\hline Aguilar et al, 2009 & Retrospective & $\begin{array}{l}\text { Diabetics with } \\
\text { heart failure }\end{array}$ & $6.4 \%$ & $\begin{array}{l}\text { Older, have chronic kidney disease, anemia and low } \\
\text { cholesterol }\end{array}$ \\
\hline $\begin{array}{l}\text { Nichols et al, } \\
\text { 2013, US }\end{array}$ & Prospective & Diabetics & $6 \%$ & $\begin{array}{l}\text { Older, more macrovascular complications, lower } \\
\text { body mass index and lower blood pressure. }\end{array}$ \\
\hline $\begin{array}{l}\text { Currie et al, 2010, } \\
\text { UK }\end{array}$ & Retrospective & Diabetics & $6.4 \%$ & $\begin{array}{l}\text { Insulin treated, older, more comorbidities and } \\
\text { longer duration of diabetes. }\end{array}$ \\
\hline Nicholas et al, 20 & Case-control & Diabetics & $6.5 \%$ & $\begin{array}{l}\text { More prevalence of vascular disease, renal failure, } \\
\text { malnutrition, smoking and weight loss. }\end{array}$ \\
\hline $\begin{array}{l}\text { Monami et al, } \\
2013\end{array}$ & Case-control & Diabetics & $6.5 \%$ & $\begin{array}{l}\text { Insulin-treated, older, longer duration of diabetes } \\
\text { and more comorbidity burden. }\end{array}$ \\
\hline $\begin{array}{l}\text { Colayco et al, } \\
2011\end{array}$ & Case-control & Diabetics & $6.4 \%$ & More prevalence of cardiovascular comorbidities. \\
\hline Carson, et al 2010 & Prospective & $\begin{array}{l}\text { General } \\
\text { population }\end{array}$ & $4.0 \%$ & $\begin{array}{l}\text { Low cholesterol, high ferritin, low blood pressure } \\
\text { and abnormal liver function. }\end{array}$ \\
\hline $\begin{array}{l}\text { Shurraw et al, } \\
2011\end{array}$ & Prospective & $\begin{array}{l}\text { Diabetics with } \\
\text { CKD }\end{array}$ & 6.5 & $\begin{array}{l}\text { Older, high level of heart, lung, liver diseases, } \\
\text { malignancy and dementia. }\end{array}$ \\
\hline Ricks et al, 2012 & Prospective & $\begin{array}{l}\text { Diabetics on } \\
\text { hemodialysis }\end{array}$ & 6.9 & $\begin{array}{l}\text { Low body weight and increased markers of } \\
\text { malnutrition and inflammation. }\end{array}$ \\
\hline
\end{tabular}

\section{Frailty as a confounder}

Studies of patients with type 2 diabetes which showed a linear relationship between $\mathrm{HbAlc}$ and mortality, without an increased risk in the lowest HbAlc categories, have enrolled younger patients with a shorter duration of diabetes and a lower comorbidity burden [44, 45]. On the other hand, patients in the studies which showed increased risk of mortality in the lower HbAlc categories were consistently older and had more prevalent comorbidities than patients in the higher HbA1c categories. Although studies have adjusted for the associated comorbidities, it is still not clear whether there is an underlying biological process that could explain the association between low $\mathrm{HbAlc}$ and allcause mortality. Patients in the lower HbA1c categories who showed high mortality may be exhibiting a different "phenotype" of type 2 diabetes. A phenotype which is likely to be frail. Frailty is a condition characterized by a reduction in physiological reserve and in the ability to resist physical or psychological stressors [18]. Frailty is viewed as a wasting disease with weight loss being one of its criteria [19]. Although frailty was not directly measured in these studies, markers of inflammation such as elevated ferritin level and markers of malnutrition such as low cholesterol, low serum albumin and weight loss were prevalent in patients with low $\mathrm{HbA} 1 \mathrm{c}$ which may suggest poor general health and underlying frailty. Also the association between low HbAlc and increased mortality were demonstrated in frail populations such as those with end stage renal disease and heart failure. Therefore, the risk of mortality in older people with diabetes could be more related to frailty than to diabetes itself or the associated comorbidity. In a cohort of 2305 individuals, aged $\geq 70$ years, of the Canadian Study of Health and Aging diabetes was more likely to be associated with medium-term mortality (HR 1.42, 95\% CI 1.20 to 1.69$)$ than comorbidity $(1.03,1.01$ to 1.05$)$. Frailty most strongly predicted death (HR $2.72,95 \%$ CI 2.34 to 3.16) after 5 years of follow up. Frail older adults were 2.62 times (95\% CI 1.36 to 5.06) more likely to have a complication of diabetes, independent of age, sex and duration of diabetes [46]. This has also been demonstrated in another prospective study which showed that frailty significantly predicts mortality in subjects with diabetes compared to those without particularly in men. Frailty increased the risk of long-term mortality by $14 \%$ (HR $1.14,95 \%$ CI 1.10 to $1.18, \mathrm{P}<0.01$ ) for each unit increase in frailty score in women and by $60 \%$ in men $(1.60,1.21$ to $2.12, \mathrm{P}<0.001)$ in the absence and by 
$31 \%(1.31,1.03$ to $1.85, \mathrm{P}<0.03)$ in women and by $60 \%$ in men $(1.99,1.75$ to $3.05, \mathrm{P}<0.001)$ in the presence of diabetes, respectively [47]. Older patients with lower $\mathrm{HbA1c}$ levels may suffer from poor nutritional status, frailty, or sarcopenia, each of which may contribute to an elevated mortality risk. Patients with diabetes have three times higher risk of sarcopenia than those without diabetes (OR 3.06, 95\% CI 1.42 to 6.62) and prevalence of sarcopenia in patients with diabetes increases significantly after the age of 60 years. Patients with diabetes have decreased lean body mass and increased body fat mass, even though they had similar BMI compared with non diabetic individuals. Also diabetic patients have weaker muscle strength even if they have normal muscle mass compared to non diabetic persons [48]. In overweight or obese (median BMI $34.0 \mathrm{~kg} / \mathrm{m}^{2}$, range $24.8-65.1 \mathrm{~kg} / \mathrm{m}^{2}$ ) older people (median age 62 years, range $51-86$ years) with diabetes, low $\mathrm{HbAlc}$ $(\leq 6.4 \%)$ was not associated with increased risk of all cause mortality which may suggest that weight loss or frailty could be a crucial contributing factor to mortality demonstrated with low $\mathrm{HbAlc}$ in other studies [49]. The beneficial effect of low HbAlc level seems to be limited to patients with low comorbidity and a long life expectancy. In an observational study of 2613 patients with type 2 diabetes to determine whether low HbAlc $(\leq 6.5 \%$ or $\leq 7.0 \%)$ provides differential benefits for patients with high versus low levels of comorbidity using Total Illness Burden Index, low HbAlc was associated with lower 5-year incidence of cardiovascular events in the low comorbidity but not in the high comorbidity subgroup. Adjusted HR was 0.60 (95\% CI 0.42 to 0.85 , $\mathrm{p}=0.005$ for low comorbidity compared to 0.92 (0.68 to $1.25, \mathrm{p}=0.61)$ for high comorbidity subgroup for $\mathrm{HbA1c}$ $\leq 6.5 \%$ and 0.61 ( 0.44 to $0.83, p=0.001)$ vs 0.88 ( 0.66 to $1.17, \mathrm{p}=0.38$ ) for $\mathrm{HbA} 1 \mathrm{c} \leq 7.0 \%$ respectively [50]. Low $\mathrm{HbAlc}$ is likely to be a marker of poor nutrition and can be seen as a biochemical marker of frailty rather than a direct cause of adverse outcomes. Similarly, other biochemical marker of under nutrition such as low albumin is a recognized predictor of frailty and poor outcomes. Low albumin $(<3.0 \mathrm{~g} / \mathrm{dL})$ has independently predicted the development of new onset disability at discharge amongst 885 patients $\geq 70$ years old who had been independent at hospital admission [51]. Also, albumin correlated inversely with the Frailty Index ( $\mathrm{r}-$ $0.545, \mathrm{P}<0.01$ ) in another study [52]. Therefore, frailty or decline in functional reserve may be an intermediate stage between poor nutrition, manifested by low $\mathrm{HbA} 1 \mathrm{c}$ or low albumin, and poor outcomes in older people regardless of diabetes status (Figure 1).

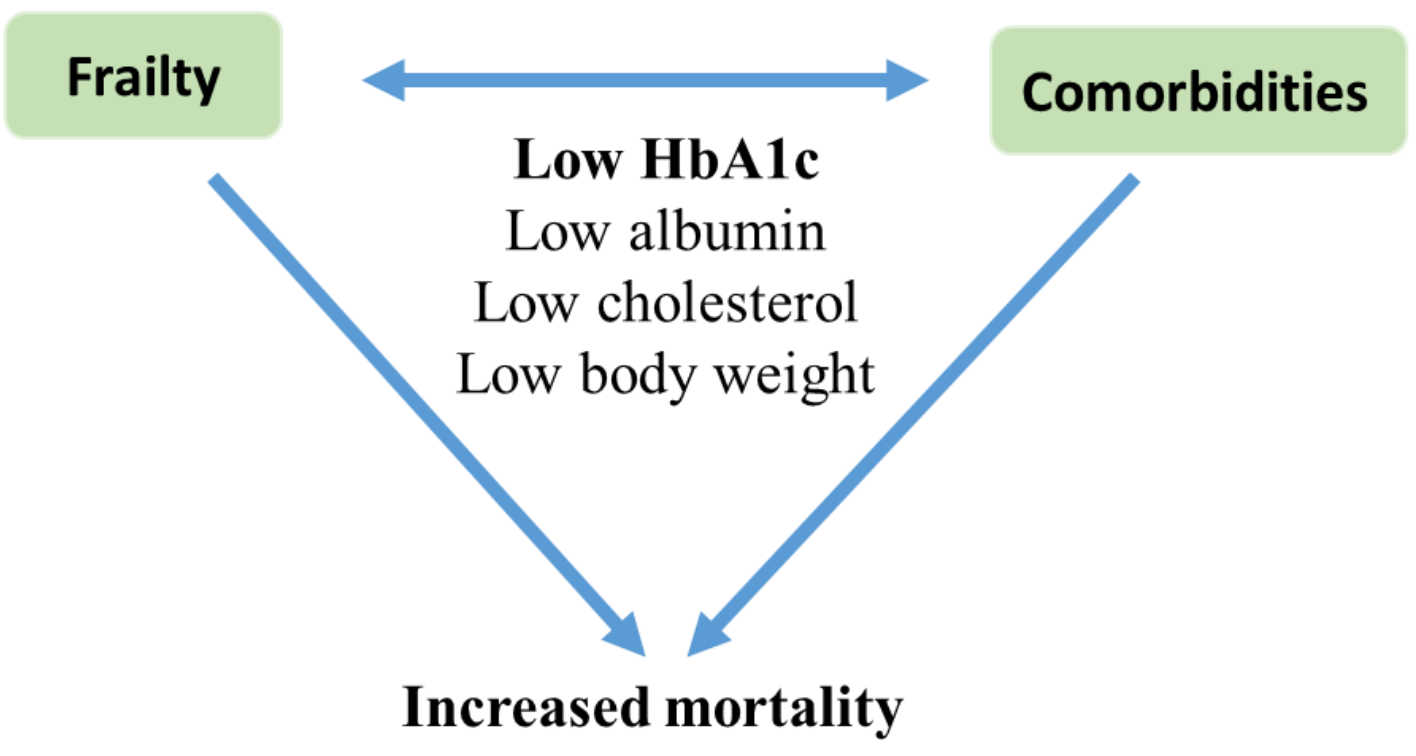

Figure 1. Frailty and comorbidities as confounders and low HbA1c and other biochemical factors as markers of increased mortality. 


\section{Reverse metabolism}

An explanation of the paradoxical relationship between $\mathrm{HbAlc}$ and mortality may include the concept of "reverse metabolism". This concept refers to the observation that the power of traditional cardiovascular risk factors such as hypertension, high cholesterol and high blood glucose to predict risk of cardiovascular disease seems to diminish with advancing age. In the general population of older people ( $\geq 85$ years) with no history of cardiovascular disease, classic risk factors included in the Framingham risk score did not predict risk of cardiovascular mortality [53]. Also the utility of the metabolic syndrome concept failed to predict mortality in the elderly and paradoxically predicted survival. In a study of 331 very old patients, mean (SD) age 85 (7) years, low BMI, low diastolic blood pressure, low total cholesterol and high insulin sensitivity predicted total mortality, indicating a "reverse metabolic syndrome" that is probably attributable to malnutrition and/or chronic disorders which have a negative impact on survival [54]. Low albumin (a marker of malnutrition) and high C-reactive protein (a marker of inflammation) were associated with these cardiometabolic factors limiting their prognostic value in predicting cardiovascular risk in older people [54]. Although there are several potential causes for this risk factor pattern, the more commonly proposed explanations include the association of lower weight and lower cholesterol with increased protein energy malnutrition and an increased inflammatory syndrome associated with frailty $[55,56]$. Another explanation is that reverse metabolism may be related to the natural physiology of the ageing process itself. The risk factors may change as an organism physiologically ages, such that a biomarker that is predictive earlier in life may not be as predictive in later life. For example, with increasing age there is a tendency towards increased blood pressure, body weight and glucose intolerance. However, when very old age is achieved there may be a metabolic shift with a tendency of these risk factors to decline in the opposite direction. In other words, there may be different connections between risk factors and mortality at different ages, with a turning point for these risk factors from unfavorable to favorable for survival outcome at older age [57].

\section{Conclusions}

The general population is aging and it appears that the epidemiology of diabetes is shifting towards older age with more that $50 \%$ of persons with diabetes are above the age of 65 years. The benefits of tight glycemic control and the linear relationship of $\mathrm{HbAlc}$ and mortality risk were mostly seen in younger populations with less comorbidities. However, with the demographic shift towards older age and its associated comorbidities along with the emergence of frailty the evidence appears to shift from a linear to a U-shaped relationship between cardiovascular risk factors including $\mathrm{HbAlc}$ and mortality. Therefore, the nature of the relationship between HbAlc and mortality may be different in different populations, it may change over time and it may be modified by other risk factors. Such factors are likely to include frailty as a major confounder as the characteristics of patients across the studies which showed increased mortality risk with low HbAlc were consistently older and had high prevalence of multiple comorbidities. In addition, frailty was not directly adjusted for in any of these studies raising the possibilities of confounding effect. Therefore, more research is needed to explore the role of frailty as a direct cause for increased mortality associated with low HbAlc.

\section{References}

[1] UKPDS Group. UKPDS 33 (1998). Intensive bloodglucose control with sulphonylureas or insulin compared with conventional treatment and risk of complications in patients with type 2 diabetes. Lancet 352: 837-851.

[2] Stratton IM, Alder AI, Neil HA, Matthews DR, Manley SE, Cull CA, et al (2000). Association of glycaemia with macrovascular and microvascular complications of type 2 diabetes (UKPDS 35): prospective observational study. BMJ 321: 405-412.

[3] Patel A, MacMahon S, Chalmers J, Neal B, Billot L, Woodward M, et al (2008). Intensive blood glucose control and vascular outcomes in patients with type 2 diabetes. N Engl J Med 358: 2560-2572.

[4] Duckworth W, Abraira C, Moritz T, Reda D, Emanuele N, Reaven PD, et al (2009). Glucose control and vascular complications in veterans with type 2 diabetes. N Engl J Med 360: 129-139.

[5] Gerstein HC, Miller ME, Byington RP, Goff DC Jr, Bigger JT, Buse JB, et al (2008). Effects of intensive glucose lowering in type 2 diabetes. N Engl J Med 358: 2545-2559.

[6] Abi KC, Roussel R, Mohammedi K, Danchin N, Marre $M$ (2012). Cause specific mortality in diabetes: recent changes in trend mortality. Eur J Prev Cardiol 19: 374381.

[7] Ricci P, Blotière P O,Weill A, Simon D, Tuppin P, Ricordeau P, et al (2010). Diabète traité en France: quelles évolutions entre 2000 et 2009? Bull Epidemiol Hebd 43: 425-431.

[8] Cheng YJ, Imperatore G, Geiss LS, Wang J, Saydah SH, Cowie CC, et al (2013). Secular Changes in the Age-Specific Prevalence of Diabetes Among US Adults. Diabetes Care. 36: 2690-2696. 
[9] Boyle JP, Thompson TJ, Gregg EW, Barker LE, Williamson DF (2010). Projection of the year 2050 burden of diabetes in the US adult population: dynamic modeling of incidence, mortality, and prediabetes prevalence. Population Health Metrics. 8: 29-40.

[10] Cowie C, Rust KF, Ford ES, Eberhardt MS, Byrd-Holt DD, Li C, et al (2009). Full Accounting of Diabetes and Pre-Diabetes in the U.S. Population in 1988-1994 and 2005-2006. Diabetes Care 32: 287-294.

[11] Valiyeva E, Russell LB, Miller JE, Safford MM (2006). Lifestyle-related risk factors and risk of future nursing home admission. Arch Intern Med 166: 985-990.

[12] Dybicz SB, Thompson S, Molotsky S, Stuart B (2011). Prevalence of Diabetes and the Burden of Comorbid Conditions Among Elderly Nursing Home Residents. Am J Geriatr Pharmacother 9: 212-223.

[13] Maddigan SL, Feeny DH, Johnson JA (2005). Healthrelated quality of life deficits associated with diabetes and comorbidities in a Canadian National Population Health Survey. Qual Life Res 14: 1311-1320.

[14] Duffy RE, Mattson BJ, Zack M (2005). Comorbidities among Ohio's nursing home residents with diabetes. J Am Med Dir Assoc 6: 383-389.

[15] Gadsby R, Barker P, Sinclair A (2011). People living with diabetes resident in nursing homes--assessing levels of disability and nursing needs. Diabet Med 28: 778-780.

[16] Gregg EW, Engelgau MM, Narayan V (2002). Complications of diabetes in elderly people. BMJ 325: 916-917.

[17] Volpato S, Bianchi L, Lauretani F, Lauretani F, Bandinelli S, Guralnik JM, et al (2012). Role of muscle mass and muscle quality in the association between diabetes and gait speed. Diabetes Care 35: 1672-1679.

[18] Bergman H, Ferrucci L, Guralnik J, Hogan DB, Hummel S, Karunananthan S, et al (2009). Frailty: An emerging research and clinical paradigm-issues and controversies. J Gerontol A Biol Sci Med Sci 62A: 731737.

[19] Fried LP, Tangen CM, Walston J, Newman AB, Hirsch C, Gottdiener J, et al (2001). Frailty in older adults: Evidence for a phenotype. J Gerontol A Biol Sci Med Sci 56A: M146-M156.

[20] Buchman AS, Yu L, Wilson RS, Schneider JA, Bennett DA (2013). Association of brain pathology with the progression of frailty in older adults. Neurology. 80: 17.

[21] Walston J, Hadley EC, Ferrucci L, Guralnik JM, Newman AB, Studenski SA, et al (2006). Research agenda for frailty in older adults: Toward a better understanding of physiology and etiology: Summary from the American Geriatrics Society/National Institute on Aging Research Conference on Frailty in Older Adults. J Am Geriatr Soc 54: 991-1001.

[22] Kalyani RR, Varadhan R, Weiss CO, Fried LP, Cappola AR (2012). Frailty Status and Altered Glucose-Insulin Dynamics. J Gerontol A Biol Sci Med Sci 67: 13001306.

[23] Beers MH, Berkow R (eds). The Merck manual of geriatrics. Medical services, USMEDSA, USHH.
Section 1. Nutritional disorders. Malnutrition; 20002004 [chapter 2]. [accessed Sept. 2014].

[24] Lee JSW, Auyeung TW, Leung J, Kwok T, Leung PC, Woo J (2010). The effect of diabetes mellitus on ageassociated lean mass loss in 3153 older adults. Diabet Med 27: 1366-1371.

[25] Landi F, Onder G, Bernabei R (2013). Sarcopenia and diabetes: Two sides of the same coin. J Am Med Dir Assoc 14: 540-541.

[26] Leenders M, Verdijk LB, van der Hoeven L, Adam JJ, van Kranenburg J, Nilwik R, et al (2013). Patients with type 2 diabetes show a greater decline in muscle mass, muscle strength, and functional capacity with aging. J Am Med Dir Assoc 14: 585-592.

[27] Rizvi AA (2009). Nutritional challenges in the elderly with diabetes. Intern J Diabetes Mellitus 1: 26-31.

[28] Nichols GA, Joshua-Gotlib S, Parasuraman S (2013). Glycemic control and risk of cardiovascular disease hospitalization and all-cause mortality. J Am Coll Cardiol. 62: 121-127.

[29] Huang E, Liu JY, Moffet HH, John PM, Karter AJ (2011). Glycemic Control, Complications, and Death in Older Diabetic Patients. The Diabetes and Aging Study. Diabetes Care 34: 1329-1336.

[30] Colayco DC, Niu F, Mccombs JS, Cheetham TC (2011). A1C and Cardiovascular Outcomes in Type 2 Diabetes. Diabetes Care 34: 77-83.

[31] Engoren M, Schwann TA, Arslanian-Engoren C, Maile M, Habib RH (2013). U-Shape Association Between Hemoglobin A1c and Late Mortality in Patients With Heart Failure After Cardiac Surgery. Am J Cardiol 111: 1209-1213.

[32] Aguilar D, Bozkurt B, Ramasubbu K, Deswal A (2009). Relationship of Hemoglobin A1C and Mortality in Heart Failure Patients With Diabetes. J Am Coll Cardiol 54: 422-428.

[33] Shurraw S, Hemmelgarn B, Lin M, Majumdar SR, Klarenbach S, Manns B, et al (2011). Association Between Glycemic Control and Adverse Outcomes in People With Diabetes Mellitus and Chronic Kidney Disease. Arch Intern Med 171: 1920-1927.

[34] Ricks J, Molnar MZ, Kovesdy CP, Shah A, Nissenson AR, Williams M, et al (2012). Glycemic Control and Cardiovascular Mortality in Hemodialysis Patients With Diabetes. A 6-Year Cohort Study. Diabetes 61: 708715.

[35] Currie CJ, Peters JR, Tynan A, Evans M, Heine RJ, Bracco OL, et al (2010). Survival as a function of $\mathrm{HbA}$ (1c) in people with type 2 diabetes: a retrospective cohort study. Lancet 375: 481-489.

[36] Nicholas J, Charlton J, Dregan A, Gulliford MC (2013). Recent HbA1c Values and Mortality Risk in Type 2 Diabetes. Population-Based Case-Control Study. PLoS ONE 8(7): e68008. doi:10.1371/journal.pone.0068008

[37] Monami M, Vitale V, Lamanna C, Bartoli N, Martelli D, Zannoni S, et al (2013). HbA1c levels and all-cause mortality in type 2 diabetic patients: Epidemiological evidence of the need for personalised therapeutic targets. Nutr Metab Cardiovasc Dis 23: 300-306. 
[38] Carson AP, Fox CS, McGuire DK, Levitan EB, Laclaustra M, Mann DM, et al (2010). Low Hemoglobin A1c and Risk of All-Cause Mortality Among US Adults Without Diabetes. Circ Cardiovasc Qual Outcomes 3: 661-667.

[39] Ray KK, Seshasai SR, Wijesuriya S, Sivakumaran R, Nethercott S, Preiss D, et al (2009). Effect of intensive control of glucose on cardiovascular outcomes and death in patients with diabetes mellitus: a meta-analysis of randomised controlled trials. Lancet 373: 17651772 .

[40] Bonds DE, Miller ME, Bergenstal RM, Buse JB, Byington RP, Cutler JA, et al (2010). The association between symptomatic, severe hypoglycaemia and mortality in type 2 diabetes: retrospective epidemiological analysis of the ACCORD study. BMJ 340: b4909.

[41] Zoungas S, Patel A, Chalmers J, de Galan BE, Li Q, Billot L, et al (2010). ADVANCE Collaborative Group. Severe hypoglycemia and risks of vascular events and death. N Engl JMed 363: 1410-1418.

[42] Goto A, Arah OA, Goto M, Terauchi Y, Noda M (2013). Severe hypoglycaemia and cardiovascular disease: systematic review and meta-analysis with bias analysis. BMJ 347: f4533 doi: 10.1136/bmj.f4533.

[43] Selvin E, Steffes MW, Zhu H, Matsushita K, Wagenknecht L, Pankow J, et al (2010). Glycated hemoglobin, diabetes, and cardiovascular risk in nondiabetic adults. N Engl J Med 362: 800-811.

[44] Eeg-Olofsson K, Cederholm J, Nilsson PM, Zethelius B, Svensson AM, Gudbjornsdottir S, et al (2010). New aspects of HbA1c as a risk factor for cardiovascular diseases in type 2 diabetes: an observational study from the Swedish National Diabetes Register (NDR). J Intern Med 268: 471-482.

[45] Elley CR, Kenealy T, Robinson E, Drury PL (2008). Glycated haemoglobin and cardiovascular outcomes in people with Type 2 diabetes: a large prospective cohort study. Diabet Med 25: 1295-1301.

[46] Hubbard RE, Andrew MK, Fallah N, Rockwood K (2010). Comparison of the prognostic importance of diagnosed diabetes, co-morbidity and frailty in older people. Diabet Med 27: 603-606.

[47] Cacciatore F, Testa G, Galizia G, Della-Morte D, Mazzella F, Langellotto A, et al (2013). Clinical frailty and long-term mortality in elderly subjects with diabetes. Acta Diabetol 50: 251-260.

[48] Kim TN, Park MS, Yang SJ, Yoo HJ, Kang HJ, Song W, et al (2010). Prevalence and Determinant Factors of
Sarcopenia in Patients With Type 2 Diabetes. Diabetes Care 33: 1497-1499.

[49] Andersson C, van Gaal L, Caterson ID, Weeke P, James WPT, Couthino W, et al (2012). Relationship between HbA1c levels and risk of cardiovascular adverse outcomes and all-cause mortality in overweight and obese cardiovascular high-risk women and men with type 2 diabetes. Diabetologia 55: 2348-2355.

[50] Greenfield S, Billimek J, Pellegrini F, Franciosi M, De Berardis G, Nicolucci A, et al (2009). Comorbidity Affects the Relationship Between Glycemic Control and Cardiovascular Outcomes in Diabetes. A Cohort Study. Ann Intern Med 151: 854-860.

[51] Mehta KM, Pierluissi E, Boscardin WJ, Kirby KA, Walter LC, Chren MM, et al (2011). A Clinical Index to Stratify Hospitalized Older Adults According to Risk for New-Onset Disability. J Am Geriatr Soci 59: 1206-1216.

[52] Hubbard RE, O’Mahony MS, Savva GM, Calver BL, Woodhouse KW (2009). Inflammation and frailty measures in older people. J Cell Mol Med 13: 31033109.

[53] de Ruijter W, Westendorp RGJ, Assendelft WJJ, den Elzen WPJ, de Craen AJM, le Cessie S, et al (2008). Use of Framinghamrisk score andnewbiomarkers to predict cardiovascular mortality in older people: population based observational cohort study. BMJ 337: a3083 doi:10.1136/bmj.a3083.

[54] Vischer UM, Safar ME, Safar H, Iaria P, Le Dudal K, Henry O, et al (2009). Cardiometabolic determinants of mortality in a geriatric population: Is there a "reverse metabolic syndrome"? Diabetes Metab 35: 108-114.

[55] Kalantar-Zadeh K, Block G, Horwich T, Fonarow GC (2004). Reverse epidemiology of conventional cardiovascular risk factors in patients with chronic heart failure. J Am Coll Cardiol 43: 1439-1444.

[56] Kopple JD (2005). The phenomenon of altered risk factor patterns or reverse epidemiology in persons with advanced chronic kidney failure. Am J Clin Nutr 81: 1257-1266.

[57] Abdelhafiz A H, Loo B E, Hensey N, Bailey C, Sinclair A (2013). The U-shaped relationship of traditional cardiovascular risk factors and adverse outcomes in later life. Aging Dis 3: 454-464. 